the decline of the Glacial period. On the supposition of a uniform rate of recession, the age of the Falls equals the length of the gorge divided by the annual recession; but the rate has been undoubtedly varied by changes in a variety of conditions, which must be allowed for. As thus qualified, Mr. Gilbert gave it as his conclusion that the maximum length of time since the birth of the Falls by the separation of the lakes is only 7000 years, and that even this small measure may need significant reduction.

In the Section of Chemistry, H. C. Bolton, of the Committee on Indexing Chemical Literature, after presenting their report showing the large amount of valuable work which was being done, read a paper on the confusion which exists in the abbreviations employed in chemical bibliography, and the desirability of uniformity in designations of scientific periodicals.

C. F. Mabery's paper "On the Products of the Cowles Electric Furnace," was of particular interest, and attracted much attention. He stated that the past year had been devoted more especially to the development of an increased commercial efficiency of the furnace, so that now 300 horse-power could by means of a large dynamo, be applied with greater economy in the results ; and by coating the charcoal employed in the furnace with lime, by soaking it in lime-water, the production of graphite was largely avoided, and a marked improvement in the working of the furnace introduced. The results-although, as compared to what would eventually be accomplished by electric smelting, they may seem crude-have reached a stage where their commercial success can be demonstrated. It was also found that when the electrodes entered the mixture in a slanting position the product was increased. They are now also moved in and out with advantage, being gradually withdrawn as the resistance falls. Prof. Mabery replied to the criticisms of Hehner of Berlin, Siemens, and others, that no new principle was involved, showing that the Cowles furnace is quite different from all hitherto constructed, and the only one of practical application by which a dynamo of 300 horse-power could be used, as by means of a resistance-box and the arrangement of the furnace, the sudden breaking of the current is prevented from burning out the dynamo. The presence of copper for the reduction of aluminium was shown to be unnecessary; and, by complete exclusion of air from the furnace, buttons of the metal were easily obtained. A product which has attracted considerable attention during the past year is obtained by reducing aluminium in presence of iron. A cast iron is formed containing sometimes as much as 10 per cent. of aluminium, and this product is used to facilitate the working of crude iron, and to introduce into the various grades a small percentage of aluminium. In the reduction of aluminium in the presence of copper a yellow product is frequently taken from the furnace, which is composed of metallic aluminium to the extent of one-half or three-fourths, the balance being silicon and copper. It is also formed in the absence of copper, and then contains a higher percentage of aluminium, and always contains nitrogen. It has a resinous lustre, and decomposes water at $100^{\circ}$.

In the Section of Physics, Prof. T. C. Mendenhall prefaced his paper on "Electric Thermometry" by saying that the strictures upon the mercurial thermometer should not be carried too far. It has been of great value, though it may now fail to meet new demands. Electric thermometry is receiving especial investigation at the Signal Office, particularly from the meteorological stand-point, with some promising results. Prof. Mendenhall reported the progress which had been made in the study of atmospheric electricity during the past year. It is not time to begin to think of the origin of atmospheric electricity. The problem is its distribution and the relation, if there be any, to weather changes. Some very interesting results have been reached. In ordinary weather the clectrical condition is undergoing constant and rather wide variations, which are very local, as two collectors only a few feet apart may give curves differing considerably, though similar in their wider variations. When an electrical storm occurs, the curves over a wide area may be similar in general outline. Prof. Mendenhall also noted a phenomenon entirely new to him ; namely, that resistance-coils, after a current it passed through them for some time, upon short-circuiting will yield a reverse current for hours. This phenomenon can no doubt be classed under the general head of polarisation, yet by simple polarisation it would be difficult to account for persistence of current. This makes caution necessary in the use of resistance-coils, in order that any effects of this kind may be carefully noted. In one instance the apparent resistance of a coil was found to increase fourfold when the current was reversed.

A paper by Prof. Abbe created some discussion. The point of the paper was that, as the force of gravity varied from the equator to the poles, 30 inches of mercury in the barometer indicated a less gaseous pressure, and consequently less density of the atmosphere, at the equator than 30 inches at the poles, and hence a correction for latitude should be introduced in allowing for refraction. He showed that, for the difference of latitude of Pulkowa and Washington, it would make $\mathrm{o}^{\prime \prime} \cdot \mathrm{I}$ difference in the refraction at $45^{\circ}$ of zenith-distance, and might be sufficient partly to account for differences in systems of star declinations which depended upon observations at great zenithdistances.

In the Section of Biology, the paper of Messrs. J. M. Coulter and J. N. Rose, giving a synopsis of the North American pines, based on leaf-structure, was of especial value from a systematic stand-point, from the fact that any species in this somewhat difficult group can at once be distinguished by the peculiarities of its minute leaf structure; and the results of the author's observations are shown to be worthy of attention from the fact that a classification based on these characters is, in its broader features, closely like that of the late Dr. Engelmann, which, as is well known, took into consideration the whole tree.

The relations of germs to disease naturally occupied a prominent place in the proceedings of the Section, and the presence of over half a dozen investigators in this line made the discussions interesting. Dr. D. E. Salmon read two papers bearing on the causes of immunity from a second attack of germ diseases. There are three possible explanations:-(I) Something is deposited in the body during the attack which is unfavourable to the germ ; (2) something has been withdrawn which is necessary to its development; (3) the tissues have acquired such a tolerance for the germ or for an accompanying poison that they are no longer affected by it. Dr. Salmon favoured the last view, and gave details of a large number of experiments to substantiate his opinion. He said that Metchinkoff's phagocyte theory was not wholly satisfactory, and that large doses of the germs were more powerful than small ones. He attributed their action to a poison which was a result of their growth, and thought that a large dose had a greater effect because the poison benumbed or killed the cells, thus giving the Bacteria a better chance to grow and to thus produce more poison.

Dr. Joseph Jastrow gave an account of some physiological observations on ants, in which he was able, by simple but ingenious means, to study the rate of walk of these insects, and stated that his results, so far as they went, confirmed the opinions of others that the smaller the animal the more rapid the step, and also the more quickly fatigue was produced. Dr. Jastrow also had some observations on the dreams of the blind, taken mostly from persons who had lost the sense of sight before the age of five. In these cases the dreams were all in terms of hearing. In the case of Laura Bridyeman the dreams were apparently based on touch. In persons who become blind between five and seven, sight terms played an important part in dreams. The relation of these facts to the development of the sightcentres was pointed out.

\section{PHOTOGRAPHIC DETERMINATIONS OF STELLAR POSITIONS ${ }^{1}$}

$\mathrm{I}^{\mathrm{T}}$ has been suggested that a short account of my work upon stellar photographs for the attainment of accurate observations might be acceptable to the astronomical section. My intention had been to attend this meeting as a listener and learner only, but I comply with the suggestion the more readily, since, by a notable coincidence, I spoke upon the same subject in this place just twenty years ago this week. It is true that my communication then was only an oral one, and never reduced to writing, for the successful establishment of the Atlantic cable, of which I had received notice that day, called me away suddenly, before the time fixed for the regular presentation ; but an elaborate written memoir upon the subject had been presented to the National Academy, ten days previous, at Northampton.

The early history of celestial photography is demonstrably and exclusively American ; and its use as a method of delicate quantitative research is very markedly so. Without entering upon

: Paper read at the Buffalo Meeting of the American Association for the Advancement of Science, August 20, 1886. 
the historical data, which are of easy access to every investigator, I may mention that No. 77 of the Astronomical Fournal contained nineteen photographic impressions of as many different phases of the solar eclipse of 1854, May 26-the moment of each impression being given to the nearest tenth of a second. These were taken at West Point, under the direction of Prof. Bartlett, of the U.S. Military Academy, and form a part of his memoir, in which he also gives the distances between the cusps, as measured by himself with the micrometer in the telescope. Ten years later, in $1864, \mathrm{Mr}$. Rutherfurd constructed the $1 I_{4}^{1}$ inch photographic object-glass which has acquired so conspicuous a place in astronomical history; and with this, in addition to its other achievements, he obtained sharp photographic stellar images, with a definition previously unknown, taking for the first time distinct impressions of stars invisible to the naked eye, in fact to the 83 magnitude for white stars.

After constructing a micrometer of great delicacy for the measurement of these plates, he measured with this the relative distances and position-angles of the stars which they contained. And in the spring of 1866 he kindly placed in my hands the results thus derived from three plates of the Pleiades, each containing two impressions, taken on the evening of March Io. One of these plates contained forty stars. Bessel's memoir upon the Pleiades, published in $\mathbf{1 8 4 4}$, gave the relative positions of fifty-four stars, measured with the Königsberg heliometer, during the years 1829 to 1841 . Six of these fifty-four do not belong within the limits of the plate (which contains about one square degree), and ten of them are too faint for the photographic record, so that sixteen of Bessel's list are wanting; but, on the other hand, there are two additional ones, not observed by him.

From this fact alone it may be perceived that among the great benefits which astronomy may be justified in expecting from celestial photography, the accurate determination of magnitudes does not find place. The chemical ac ion of the stellar light upon the film is so dependent upon the character of that light that, in the absence of a correct knowledge of its composition, we are very easily deceived regarding the amount. Thus one of Bessel's stars which was not recorded upon any of Mr. Rutherfurd's plates is estimated by Argelander as of the magnitude $8{ }^{\circ} \mathrm{O}$, and by Wolf as $7 \frac{3}{4}$, while five are distinctly recorded which Argelander calls $8 \frac{1}{2}$ or less, and eight which Wolf so estimates. The spectroscope would doubtless show a deficiency of the more refrangible rays in the light of the former, and a preponderance of the same in that of the latter.

This series of measurements by Mr. Rutherfurd, together with the computations to which the results were submitted, constitute, if I am not mistaken, the first application of the photographic method to exact astronomical determinations. And the investigation necessarily demanded especial care, both for guarding the numerical results against sources of unsuspected error and for fixing the limits within which known theoretical errors would remain unappreciable.

The importance of the successful application of a method so different from all previous ones, and so full of promise, and also the considerable time which would inevitably elapse before the memoir could be printed, led me at the same time to communicate to the Astronomische Nachrichten, at Altona, some of the resultant values. In a comparatively short note, written about the middle of August 1866, I gave for the ten most conspicuous stars of the Pleiades, after Alcyone, the corrections derived from one of the photographic plates of March IO, for the values, published by Bessel, for the position-angles and distances, from Alcyone in 1840, as likewise the average discordance found for a single measure.

In the next following year the Academy had not the means of printing its memoirs; and as in the meanwhile Mr. Rutherfurd had measured five more of the plates of the Pleiades previously taken, as well as six additional ones taken in the months of January and February 1867 , these were also computed, and the results added to those from the first three plates in the memoir already written.

Various circumstances combined to delay the publication, chief among them being what seemed to me a manifest impropriety in printing the results derived from photographs and measurements made by Mr. Rutherfurd, and by his own methods, before some account of these methods should have been published by him. His communication on the subject had been made to the National Academy immediately previous to my own, but was not yet in such form as he desired for publicition.
The result showed a very remarkable accordance with Bessel's determination for $\mathbf{1} 840$, although the total amount of relative proper motion during the elapsed twenty-six years was comprised in the differences.

This memoir still remains in its original form, but unpublished; the results being deduced from twenty-four photographic impressions upon fourteen plates.

In the next year, I 868 , I had the gratification of receiving from Mr. Rutherfurd the results of his measurements of thirtytwo stars of the cluster Presepe, derived from eleven impressions. These were computed in the same way that those of the Pleiades had been, and an analogous memoir upon this cluster was prepared for the National Academy.

Before leaving the country, early in 1870 , I gave these two memoirs to Mr. Rutherfurd, with the request that he would send them to the printer, at the same time with his own paper, already mentioned, but not before then. The condition of his health prevented him from attending to the matter for some time, and in the interval he arrived at the unpleasant discovery that the screw of his micrometer had suffered from wear, and to an extent which led him to fear a want of that accuracy of which the method is susceptible, and which he hoped to see demonstrated by its very first applications.

Notwithstanding this possible blemish, it seems to me that the results ought to be now made public in their original form, after due mention of the circumstances; and it is among my hopes to be able soon to publish these two memoirs from the original manuscript of so many years ago.

The method was received with manifest distrust and disregard abroad; and, as was but natural for so essential a deviation from former methods, very many grounds of criticism and objection were brought up. One of the principal of these was the possible distortion of the collodion film, after receiving the impressions and before the measurements; but Mr. Kutherfurd speedily disposed of this point, at least so far as the albumenised plates are concerned ; and, moreover, the combination of measurements of the same stars derived from various plates will at once make manifest the degree of confi ence to which the several values and their wear are respectively entitled.

A far more serious obstacle to accuracy is presented by the difficulty of obtaining absolutely round images. Irregularity of form in the dots formed by the stellar impressions is almost in compatible with precision of measurement; and, as the time of exposure must often be long, the chief problem was, not so much to obtain the images as to insure uniformity of motion in the telescope during the period of exposure. Not that the photographic processes were not troublesome enough before the introduction of the dry-plate processes, for very great care and numerous precautions were often necessary to prevent the plates from drying too fast : but far the greatest difficulty consisted in obtaining sufficient precision in the clockwork and equatorial motion of the telescope.

It may easily be imagined how great was my desire, when leaving home for South America, to extend this new method of observation to the southern hemisphere. But the obstacles encountered in the endeavour cannot be easily imagined. Upon these I will not enlarge here further than by saying that in Cordova also the attainment of circular dots for the star images offered incomparably the greatest of all the difficulties of a practical character. The time of exposure was limited by the maximum size allowable for the large stars, and, previous to 1878 , also by the drying of the plate, although exposures of twenty minutes were not unusual. Nevertheless, by dint of specially constructed governors and regulators, and by ceaseless attention, we did succeed in obtaining impressions which, to the unaided eye, appear absolutely round.

This necessity of long-continued and minute uniformity in the motion of the telescope is, of course, largely diminished by the employment of instruments of large aperture, inasmuch as the necessary time of exposure is diminished in the same ratio in which the amount of light is increased. It is yet further and most notably diminished by the manifold greater sensitiveness of the dry gelatine plates. But notwithstanding all this, the attainment of round images, while almost indispensable for giving to stellar photography that increased accuracy to which it may lay claim as a means of research in practical astronomy, still demands especial care and precaution.

The Argentine Government cordially afforded every assistance which I deemed it proper to ask for these investigations. And although the chief energies of the Cordova Observatory 
were absorbed by those investigations for which the institution was established, I hat the satisfaction of obtaining a sufficient number of stellar photographs to occupy not only my own lifetime, but many more, in their measurement and proper computation.

We photographed no northern stars there except the Pleiades and the Pirsepe. Of the Pleiades I hrought home sixteen plates, with two impressions of the whole group upon each, made in five different years, from 1872 to 1882 , inclusive. Although the centre of the cluster never attains a greater altitude at Cordova than $34^{\circ} 50^{\prime}$, some of the plates contain seventy stars. All but one of Bessel's stars are there, which belong within the limits of the field, the missing one being of the magnitude $9 \frac{1}{2}$, and there are yet other stars of the magnitudes IO, IO $\frac{1}{2}$, and II. Of the Presepe there are five plates, and with a correspondingly increased number of stars.

A bout seventy southern clusters have been repeatediy photographed at Cordova, comprising all those of the southern hemisphere which seemed important, al:o somewhat more than a hundred double stars, being a sufficient number to serve as a good test of the method. The total number of photographs now on hand is somewhat less than $\mathrm{r} 300$, only few having been preserved in which the images were not circular.

Especial attention, however, was given for many years to taking frequent impressions, at the proper seasons, of four stars selected, on account of their large proper motion, as likely to manifest appreciable annual parallaxes. The refined and elaborate o!sservations of lirs. Gill and Elkin, at Cape Town, have been made, computed, and published, while the Cordova photographs have lain untouched in their boxes. There is but one of my four stars, $\beta$ Hydri, which is not included in their list. Still, it will be a matter of much interest to apply the photographic investigation to the same problem, even if for no other purpose than a comparison of the results of the two methods.

I am convinced that the Cortova plates contain a large num. ber of stars as faint as the eleventh magnitude of Argelander's scale, and believe that the se are much the earliest photographs of stars fainter than Mr. Rutherfurd's of 1865 and I866. There are several plates, covering about a degree square, which cannot contain less than $55^{\circ}$ stars, and I believe that some of them contain a greater number. Such are those of the cluster Lac. 4375 and that near X Carinæ.

The recion in the vicinity of $\eta$ Carinæ, and that magnificent tract in Sagittarius which is too densely sown with stars to be considered merely a portion of the Milky Way, and yet too large and undefined to be regarded simply as a cluster, were both of them taken several times, during the years $1875-82$, in series of overlapping photographs, each containing about a quare degree, and recorded upon a glass surface of 9 by 12 centimetres. In their present form they are of course of small value for scientific use, inasmuch as the stars are too crowded for their configurations to be easily perceived; and although these two series form, in fact, maps of considerable regions in the sky, still the record is of a very perishable nature, and of small avail for use by astronomers until it shall have been translated into an enduring and numerical form by micrometric measurement.

In this connection I may say that one of the greatest of my present anxieties regarding the Cordova photographs arises from a discovery of the ease with which the collodion or gelatine film may become detached from the glass. The Argentine Government has assigned a moderate sum for the prosecution of the measurements, and with this some progress has already been made. It is but right to add that the full amount was given for which I aslied. Still, it is now quite inadequate, in consequence of the unfortunate depreciation of the national currency; and, in the present financial crisis there, I cannot reasonably expect more. Yet this matter of prompt measurement appears to me at present much more important than it did while I was unaware of the facility with which the film can blister and peel.

In I883, after Mr. Common's brilliant success in photographing nebulas with his great 3 -foot reflector, he proposed to me joint arran rement for photographing the whole heavens. My work at Cordova was so near its close that it was out of the question to undertake anything new; but the immense labour requisite for the measurement of the plates would, under any circumstances, have tended to deter me. It is an undertaking demanding the joint energy, application, and material resources of a large number of persons, if the results are to be made avail- able for astronomical use ; indeed, I see no other astronomical value in the unmeasured photographs than the possibility of confirming at some future epoch the existence of relative motion previously detected or made probable by some other investigation.

Since then the process of photographic charting is said to have been systematically undertaken by the Brothers Henry at Paris. I have seen none of their plates; but their sharpness is highly spoken of, and the work appears to be prosecuted with much skill and very sensitive plates. There can of course be no question as to the value of any permanent record whatsoever, corresponding to a known date; yet I cannot feel that any essential advance is likely to be made in this way until the photographic record shall have been brought within the range of numerical expression.

The measurements of the Cordova photographs, thus far completed, are those of the double stars, the four stars with large proper motion, of the Pleiades, of the Prasepe, and of the clusters Lac. 4375 and $k$ Crucis. The corresponding computations have been made, as yet, only for a portion of the Pleiades impressions, but I am hopeful of completing all these at a comparatively early date. We shall then be able not only to compare the results with Bessel's of forty-five years ago, but to test the deduced values of the proper motions by means of the photo rraphic determinations of 1865 and I866. Meanwhile, the valuable memoir of Wolf has been published, giving closely approximate positions for $57 \mathrm{I}$ stars of the group, and Dr. Elkin has recently been executing at New Haven a heliometric triangulation of the principal stars. Our photographic results will have to be confronted with his delicate heliometric ones; and should they bear this test with tolerable success, it will be al that can reasonably be desired.

B. A. Gould

\section{UNIVERSITY AND EDUCATIONAL INTELLIGENCE}

Prof. W. Grylis Adams, F.R.S., will deliver, at King's College, London, a course of lectures on Electricity and Magnetism and their applications to Electric Lighting, Transmission of Power, \&c., during the academical year 1886-87. A course of practical work in Electrical Testing and Measurement with especial reference to Electrical Engineering will also be carried on under his direction in the Wheatstone Laboratory. In the Wheatstone Laboratory, which is open daily for research from I to 4, except on Saturdays, there are special course; of practical work $f$ or students preparing for the Science Examinations of the University of London.

IT is purposed to celebrate, in a befitting manner, from November 6 to 8 next, the 25 oth anniversary of the founding of Harvard University, Cambridge, Massacbusetts. The University was established on November 7,1636 , by an Act of the Colonial Le sislature, and was named after John Harvard, who was a liberal benefactor of the new in titution. Harvard is the oldest University in North America. The southern portion of the Continent possesses one many years older-the University of St. Mark, at I ima, founded in $155 \mathrm{I}$ by the Emperor Charles V.

\section{SCIENTIFIC SERIALS}

Buldetin de l'Académie Royale de Belgique, July.-Modern kinetics and the dynamism of the future, by G. A. Hirn. The author replie; to the arguments urged by $\mathrm{M}$. Clausius against his view of the kinetic theory in its application to the resistance of gases. He continues to treat the question in connection with his peculiar spiritualistic opinions, and endeavours to overthrow the theory now generally accepted by physicists, beciuse of the disastrous consequences which he supposes it would have on the progress of mankind.-On a class of conjugated polynomes, by $\mathrm{J}$. Deruyts. This memoir, which is a further development of the author's previous researches, deals more especially with the important functions presented by certain polynomes in the approximate calculation of definite integrals. - On the distribution of the regenerate nerves, by C. Vauclair. In this paper the author deals with the peripheric distribution of the regenerate nerves compared with that of the primitive nervous system.Essay on the origin of the Fraunhofer rays in relation to the 